\title{
Relationship between Stress Symptoms and Drug use among Secondary Students
}

\author{
Iracema Francisco Frade, Denise De Micheli, André Luiz Monezi Andrade and \\ Maria Lucia Oliveira de Souza-Formigoni \\ Universidade Federal de São Paulo (Brazil)
}

\begin{abstract}
The aim of this study was to evaluate the relationship between drug use and four kinds of stress symptoms in 954 Brazilian students from the $6^{\text {th }}$ to the $11^{\text {th }}$ grades, in 4 public and 5 private schools in the city of Sao Paulo. Based on their answers to the Drug Use Screening Inventory (DUSI-R) and to the Stress Scale for Adolescents (SSA), we compared regular drug users with non/occasional drug users regarding the frequency of four kinds of stress symptoms (psychological, cognitive, physiological, interpersonal), and the period in which it happened. When compared to non/occasional drug users, regular drug users presented higher levels of psychological, cognitive and physiological symptoms of stress and these symtoms were in the most severe spectrum of severity (near to exhaustion and exhaustion). The association between drug use and stress was even stronger in the youngest age group (11 to 13 years old). Most of the regular drug users were 16 years old and over, from upper-middle class families, had poor family relationships and more academic problems. These results confirm the association between drug use and stress in adolescents and highlight the need for early screening and intervention in both drug use and stressful situations.
\end{abstract}

Received 18 May 2011; Revised 30 November 2011; Accepted 10 January 2012

Keywords: adolescence, stress, drug abuse, questionnaire.

There have been reports on the use of alcohol to relieve stress since ancient times. The concept of "drinking to relax", in addition to drinking in social settings, has had a strong influence in different cultures (Sayette, 1999). According to the stress-reducing theory, some people use alcohol for its anxiolytic and stress-reducing effects, since this helps them to cope with stressful situations (Conger, 1956). Most theories of drug dependence assume that stress plays an important role in increasing drug use and also in triggering relapse (Campbell, Szumlinski, \& Kippin, 2009; Ungless, Argilli, \& Bonci, 2010). Moreover, studies in animals and humans have shown that exposure to stress increases the self-administration of drugs (Caldwell \& Riccio, 2010; Erb, 2010; Weiss et al., 2001). Interestingly, Farber, Khavari, \& Douglass (1980) reported that while most of the social drinkers used alcohol for its positive reinforcing effects (pleasant mood, celebration, sociability), $93 \%$ of a sample of alcoholics used alcohol for

Correspondence concerning this article should be addressed to Maria Lucia Oliveira de Souza-Formigoni. Rua Botucatu 862. $1^{\circ}$ andar. 04023062. São Paulo (Brazil). Phone: +55 (11) 21490155.

E-mail: mlosformigoni@unifesp.br.

This study was developed as the Master's thesis of the first author (Frade, I. "Uso de substâncias psicoativas e estresse em adolescentes brasileiros: Uma relação complexa" [Stress and use of psychoactive substances by Brazilian adolescentes: a complex relation] approved by the Programa de Pós-Graduação em Psicobiologia da UNIFESP in 2004). This research was supported by Associação Fundo de Incentivo à Pesquisa (AFIP). The authors wish to thank Maria Helena Pagdi for her linguistic suggestions. its negative reinforcing properties (stress reduction). In addition, the use of ethanol tended to be high in individuals with high levels of stress and anxiety (Kushner, Sher, \& Beitman, 1990; Terra et al., 2006). Most of the studies on the relationship between stress and substance abuse were carried out in adult drugdependent individuals (Battista, Stewart, \& Ham, 2010; DeMartini \& Carey, 2011). There are few studies on this issue in the adolescence period, although this is the most critical and susceptible period to start using drugs (Ernst \& Korelitz, 2009; Ernst, Romeo, \& Andersen, 2009; Silva, Malbergier, Stempliuk, \& de Andrade, 2006).

In Brazil, some surveys carried out with representative samples of students (Galduróz, Noto, \& Carlini, 1997; Carlini et al., 2010) and general population (Galduróz, Noto, Nappo, \& Carlini, 2005) indicated that the use of alcohol and other drugs usually begins in adolescence. Considering all adolescent age brackets (10-18 years), $15 \%$ of adolescents were considered frequent users of alcohol, $6.2 \%$ of tobacco and 3.3\% of other drugs. Besides, half of the students (51.2\%) in the 10-12 age bracket had already made use of alcohol, $11 \%$ of tobacco, and $11.7 \%$ of other drugs.

According to many reports, exposure to stress in adolescence is significantly associated with the use of alcohol and drugs (Agnew \& White, 1992; Hoffmann, Cerbone, \& Su, 2000; Hoffmann \& Su, 1998; KochHattem \& Denman, 1987; Shahtahmasebi \& Berridge, 2009). However, few studies take into account the different kinds of stress or its stage (Tarter, Blackson, 
Brigham, Moss, \& Caprara, 1995). Stress is a process that involves both cognitive and affective perceptions of a stressful event, the development of coping strategies and the production of biological, behavioral and cognitive responses (Sinha, 2001). Selye (1956) defined this set of non-specific reactions that the body develops in the face of stressors as the "General Adaptation Syndrome". It manifests itself in three distinct stages: alarm or alert stage, resistance stage and exhaustion stage. Lipp (2000) proposed the inclusion of a fourth stage to Selye's triphasic model: the "near exhaustion" stage, which corresponds to the second half of the resistance stage where the body's energy is nearly depleted. Tricoli (2002) validated an instrument (Stress Scale for Adolescents - SSA) to evaluate the psychological, cognitive, physiological and interpersonal aspects of stress, classifying them according to the stages proposed by Lipp (2000). Cerbone \& Larison (2000) pointed out the need for studies that use standardized instruments and also focus on other factors, such as the cultural context, to allow for a more adequate evaluation of the complex relationship between stress and drug use, since there are many other issues associated with both in this period, such as school performance (Wechsler, Davenport, Dowdall, Moeykens, \& Castillo, 1994), living arrangements (De Micheli \& Formigoni, 2004) and neurobiological vulnerabilities (Ernst \& Korelitz, 2009).

This study aimed to evaluate the association between different kinds of stress symptoms and the use of psychoactive substances by Brazilian secondary students, comparing regular drug users with non/occasional drug users regarding the frequency of four kinds of stress symptoms (psychological, cognitive, physiological, interpersonal) as well as the period it happened and its stage of severity. We hypothesized that if stress plays an important role on substance use, then regular drug users will display higher prevalence and severity of stress symptoms than non/occasional drug users. Besides, some specific kinds of stress (psychological, for instance) may be more strongly related to drug use than others. We also hypothesized that the level of association between stress and drug use may be different in the different age brackets - being more important at younger phases.

\section{Method}

\section{Participants}

We used a convenience sample comprising 979 students of both genders, aged between 12 to 19 years. They were students between the $6^{\text {th }}$ and $11^{\text {th }}$ grades of 9 different schools in the city of São Paulo, Brazil; 4 were public schools and 5 were private. The classes that participated in this study were randomly selected through a raffle based on the attendance lists provided by each school. We used the program Epi-Info version 1.1.2 to generate the samples, which included at least $20 \%$ of the total number of students of each grade and school.

\section{Instruments}

The questionnaire used for the collection of data on sociodemographic status, family relationship, school situation and extracurricular activities was devised by the authors of this study. The version of the Drug Use Screening Inventory (DUSI-R) was developed by Tarter et al. (1995) and by Kirisci, Mezzich, and Tarter (1995). ${ }^{1}$ The instrument was validated to be used with Brazilian adolescents by De Micheli and Formigoni $(2000,2002 b)$ and has already been applied in previous Brazilian studies (Dalla-Dea, De Micheli, \& Formigoni, 2003; De Micheli \& Formigoni, 2002a).

The DUSI-R is a self-report questionnaire which has 159 questions that measures the frequency of use in the previous month, as well as associated problems in 10 areas: substance use, behavior, health, psychiatric disorders, social, family, school and work competence, peer relationship and leisure/recreation. We determined the Absolute Density of Problems in each area by dividing the number of affirmative answers by the total number of questions in the area, then multiplying by 100 . The percentage obtained represents the intensity of problems in the area evaluated. In this study we excluded the questionnaires with unanswered questions $(2.5 \%)$ in Substance Use area. Based on the scores in this area, we classified the students as non-users / occasional drug users (those with up to 2 affirmative answers, which is equivalent to $13.3 \%$ of the absolute density of Substance Use area) and regular drug users (those with 3 or more affirmative answers). A total of 758 students $(79.5 \%)$ out of 954 were classified as "Non-users/occasional drug users" and 196 students (20.5\%) were classified as "Regular drug users".

The Stress Scale for Adolescents (SSA), named [Escala de Stress para Adolescents (ESA) in Portuguese], is an instrument developed in Brazil by Tricoli (2002). It was based on the Stress Scales for Adults (Lipp, 2000) and children (Lucarelli \& Lipp, 1999). We have chosen this instrument because it is the only questionnaire for the evaluation of stress that used a sample of Brazilian adolescents in its validation. The SSA is a Likert scale, where each of the 44 alternatives is associated with a relative score of symptom frequency [(0) "never feels it" (1) "rarely feels it", (2) sometimes feels it", (3) "almost always feels it" or (4) "always feels it"] and a score reflecting the period in which the situation

${ }^{1}$ Detailed information available at: http://pubs.niaaa.nih.gov/ publications / AssesingAlcohol/InstrumentPDFs/32_DUSI-R.pdf 
occurred [ranging from (0) "it did not happen" (1) "it has happened in the last 24 hours", (2) "it has happened in the last week" (3) "it has happened in the last month" or (4) "it has happened in the last 6 months]. This instrument was submitted to construct validation by factor analysis and comprises four subscales corresponding to four factors: psychological symptoms (24 questions), cognitive symptoms (6 questions), physiological symptoms (9 questions) and interpersonal symptoms (5 questions). Some examples of SSA questions are: "I feel back pain" (physiological symptom); "I feel insecure" (psychological symptom); "I get a lot of time alone" (interpersonal symptom) and "I have had difficulties regarding studying" (cognitive symptom). These questions are presented in a random order in the questionnaire. The subscales scores are calculated by the sum of the answers to the questions within the same factor. A total score is obtained by the sum of the subscales scores. As proposed by Tricoli (2002), considering each subscale, the adolescents who scored up to the first quartile (the lowest scoring 25\%) were classified as "non-stressed", those who scored from the third quartile on (the highest scoring $25 \%$ ) were classified as "stressed" and those who were in the intermediate $50 \%$ were classified as "vulnerable". Regarding the frequency of symptoms, the cutoff points (quartiles Q1 and Q3) for each of the four subscales were defined as follows: psychological symptoms: 36 and 61; cognitive symptoms: 8 and 14; physiological symptoms: 13 and 20; and interpersonal symptoms: 6 and 10 . Regarding the period in which it happened, the scale's cutoffs used to classify stress stages were: up to 24 : "no stress"; between 25 and 46: "alert"; between 47 and 66: "resistance"; between 67 and 88: "near-exhaustion" and above 88: "exhaustion".

\section{Procedures}

Adolescents were invited to participate in the study by the researcher who had received prior consent from the school director in each of the schools. All participants were informed of the research objectives and assured that the data would be confidential. They were then asked to read and sign a consent form developed in accordance with the guidelines of the Committee of Ethics in Research of the Universidade Federal de São Paulo (UNIFESP), which approved the project (CEP 0193/003). The questionnaires were administered in the classrooms in the absence of teachers or any other school employees. Only the main investigator and a trained auxiliary were present. Neither of them had had any previous contact with the students. After the researchers distributed the questionnaires, they instructed the students on how to fill them out and emphasized that their participation was voluntary.
They also requested that students give honest answers and not leave any questions unanswered. All of the participants were formally and explicitly assured that only the persons involved in the research would have access to the results and that under no circumstances would the answers be provided to parents, teachers or the school director. The students were informed that they did not have to identify themselves and were asked to put the questionnaires in a box placed in front of the classroom when finished to preserve their anonymity.

After the administration of the SSA scale, the students evaluated their degree of difficulty in answering it and whether it had been an unpleasant task. Only 2\% of the students deemed it difficult to answer the SSA scale, and less than $10 \%$ considered it unpleasant to respond to.

\section{Statistical Analysis}

We used the Chi-square test $\left(\chi^{2}\right)$ to assess the association between sociodemographic variables (e.g. gender, living arrangements, socioeconomic classification and others), the presence of four types of stress (psychological, cognitive, physiological and interpersonal), the frequency of drug use in the last 30 days (did not use, used one or two times, used between three and nine times, used more than 20 times) and being considered a regular or a non/occasional drug user. We considered the "expected frequency" was $20.5 \%$ in the group of regular drug users and $79.5 \%$ in the non-users / occasional drug users, that is, the proportions observed in the total sample. The comparison of subscales scores between groups (non/occasional vs. regular drug users) was made by Student's t-test (when the distribution of the dependent variable was normal) or by Mann-Whitney test (when there was no normal distribution). We used the Kruskal-Wallis's test, followed by the Mann-Whitney's tests to compare groups classified according to the intensity of stress symptoms and the Spearman's correlation to assess the degree of association between the variables. The level of significance was set at $5 \%$.

\section{Results}

\section{Profile of the sample}

Table 1 presents the sociodemographic data of the sample studied. The total sample $(n=954)$ was composed of $47.6 \%$ girls and $52.3 \%$ boys. Regarding the use of drugs, $79.5 \%$ were classified as non-users/occasional (NOC) drug users and $20.5 \%$ as regular drug users. The percentage of girls who were regular drug users (21\%) was similar to that of boys (19.7\%). We found significant differences between age groups in the 
Table 1. Sociodemographic data and school situation of secondary school students classified as "Non-users/occasional drug users" or "Regular drug users". The first two columns of the table represent the percentage of students in each category (non-users and regular drug users). The data in the third column represents the proportion (\%) of each category in relation to the total sample

\begin{tabular}{|c|c|c|c|c|c|}
\hline & $\begin{array}{l}\text { Non/ocasional } \\
\text { users }(n=758) \\
(79.5 \%)\end{array}$ & $\begin{array}{l}\text { Regular users } \\
(n=196) \\
(20.5 \%)^{\mathrm{a}}\end{array}$ & $\begin{array}{l}\text { Percentage } \\
\text { of the total } \\
\text { sample }(n=954)\end{array}$ & $\begin{array}{l}\chi^{2} \text { or } T \\
\text { value }\end{array}$ & $p$ \\
\hline \multicolumn{6}{|l|}{ Gender: } \\
\hline Female & 79 & 21 & 47.6 & $\chi^{2}=.13$ & n.s. \\
\hline Male & 80 & 19.7 & 52.3 & $\chi^{2}=.20$ & n.s. \\
\hline \multicolumn{6}{|l|}{ Age: } \\
\hline From 11 to 13 & 96 & $4^{*}$ & 29.8 & $\chi^{2}=46.7$ & $<.001$ \\
\hline From 14 to 16 & 80 & 20 & 50.6 & $\chi^{2}=.13$ & n.s. \\
\hline Over 16 & 53 & $47^{*}$ & 19.6 & $\chi^{2}=80.8$ & $<.001$ \\
\hline Means \pm SD (years) & $14.3 \pm 1.6$ & $15.9 \pm 1.5^{*}$ & $14.6 \pm 1.7$ & $\mathrm{~T}=-12.6$ & $<.001$ \\
\hline \multicolumn{6}{|l|}{ Living Arrangements (lives with): } \\
\hline Both parents & 80 & 20 & 70.4 & $\chi^{2}=.04$ & n.s. \\
\hline Only with mother & 78 & 22 & 20.6 & $\chi^{2}=.13$ & n.s. \\
\hline Only with father & 64 & 36 & 1.2 & - & - \\
\hline Relatives or friends/institution/alone & 89 & $11^{*}$ & 7.8 & $\chi^{2}=4.13$ & $<.04$ \\
\hline \multicolumn{6}{|l|}{ Family Relationship: } \\
\hline Good & 82 & 17.7 & 81 & $\chi^{2}=3.56$ & n.s. \\
\hline Regular / Bad & 67 & $33^{*}$ & 19 & $\chi^{2}=16.9$ & $<.001$ \\
\hline \multicolumn{6}{|l|}{ Socioeconomic Classification } \\
\hline Upper/Upper-Middle & 77 & 22.9 & 88 & $\chi^{2}=2.65$ & n.s. \\
\hline Middle/Lower-Middle/Lower & 92.2 & $7.8^{*}$ & 12 & $\chi^{2}=10.1$ & $<.001$ \\
\hline \multicolumn{6}{|l|}{ Type of School: } \\
\hline Public & 89.3 & 10.7 & 50 & $\chi^{2}=28.4$ & $<.001$ \\
\hline Private & 69.7 & $30.3^{\mathrm{b}}$ & 50 & $\chi^{2}=28.4$ & $<.001$ \\
\hline \multicolumn{6}{|l|}{ School Level: } \\
\hline $6^{\text {th }}$ grade of Elementary School & 96.2 & $3.8^{*}$ & 14.0 & $\chi^{2}=22.5$ & $<.001$ \\
\hline $7^{\text {th }}$ grade of Elementary School & 93.6 & $6.4^{*}$ & 19.7 & $\chi^{2}=23.6$ & $<.001$ \\
\hline $8^{\text {th }}$ grade of Elementary School & 82.7 & 17.3 & 20.5 & $\chi^{2}=1.1$ & n.s. \\
\hline $1^{\text {st }}$ grade of High School & 83.5 & 16.5 & 17.8 & $\chi^{2}=1.76$ & n.s. \\
\hline $2^{\text {nd }}$ grade of High School & 54.5 & $45.5^{*}$ & 10.6 & $\chi^{2}=37.6$ & $<.001$ \\
\hline $3^{\text {rd }}$ grade of High School & 57.2 & $42.8^{*}$ & 17.4 & $\chi^{2}=50.6$ & $<.001$ \\
\hline \multicolumn{6}{|l|}{ Academic underachievement: } \\
\hline No & 81.6 & 18.4 & 89.5 & $\chi^{2}=2.1$ & n.s. \\
\hline One year delayed & 65.8 & $34.1^{*}$ & 8.7 & $\chi^{2}=8.9$ & $<.003$ \\
\hline Two or more years delayed & 41.2 & $58.8^{*}$ & 1.8 & - & - \\
\hline Extracurricular Activities & 77.7 & 22.3 & 78.7 & $\chi^{2}=1.6$ & n.s. \\
\hline Foreign languages & 88.0 & 22.0 & 35.7 & $\chi^{2}=.45$ & n.s. \\
\hline Physical Activities & 76.2 & 23.8 & 53.6 & $\chi^{2}=3.46$ & n.s. \\
\hline Others & 80.4 & 19.6 & 23.6 & $\chi^{2}=.10$ & n.s. \\
\hline \multicolumn{6}{|l|}{ Hours/week (extracurricular) } \\
\hline Less than 4 hours & 81.1 & 18.9 & 43.2 & $\chi^{2}=.48$ & n.s. \\
\hline More than 4 hours & 75.3 & $24.7^{*}$ & 56.8 & $X^{2}=4.68$ & $<.03$ \\
\hline
\end{tabular}

*Differs from non-users $p<.05$.

aPercentage observed in the total sample

${ }^{b}$ Differs from public schools. n.s. non-significant differences. In the third column, the percentages are the distribution in the total sample. In extracurricular activities, the total percentage is higher than $100 \%$ because there were participants engaged in more than one kind of extracurricular activity.

proportion of regular drug users $(p<.001)$, with a marked increase at older ages. While we detected $4 \%$ of regular drug users in the 11-13 year age bracket, this proportion was five times higher in the 14-16-year-old age bracket (20\%) and over eleven times higher among those over the age of 16 (47\%). Compared to non-users / occasional drug users, the regular drug users reported significantly $(p<.001)$ poorer family relationships 
(33\%) and were more likely to come from upper/ upper-middle-class families $(22.9 \%)$ and to study at private schools $(30.3 \%)$. While students with low academic achievement represented $10.5 \%$ of the total sample, this proportion was significantly higher $(19.7 \%)$ in the group of regular drug users $(p<.001)$ than in the group of non-users/occasional drug users $(8.2 \%)$. There was a trend toward a higher proportion of regular drug users among those who spent more than four hours/week on extracurricular activities $(24.7 \%)$ compared to those who spent less than four hours/week on the same kind of activities (18.9\%).

\section{Use of alcohol and other drugs in the past 30 days}

Table 2 presents the data on the use of drugs in the last 30 days. It shows that about half of the students used some kind of drug in that period. In the group of regular drug users, alcohol was the drug most frequently used by the students $(91.4 \%), 3 \%$ of whom reported use-related problems and $30 \%$ of whom considered it their favorite drug. Tobacco was the second most used drug (49\%), with $4 \%$ of students reporting use-related problems and $11.7 \%$ considering it their favorite drug. Analgesics without prescription came in third (41\%). Marijuana was the fourth most used drug (33\%); $1.5 \%$ of the students reported marijuana use-related problems and $13.8 \%$ considered it their favorite drug. Inhalants and solvents were in the fifth place in terms of frequency of use $(23.8 \%) ; 1 \%$ of the students reported inhalant and solvent use-related problems and $3.6 \%$ considered such drugs their favorite.

Table 3 shows the proportion of non-users/occasional drug users and regular drug users classified according to stress severity and the mean scores in the psychological, cognitive, physiological and interpersonal symptoms subscales. We observed a higher proportion of students classified as "stressed" among regular substance users when compared to both the total sample and the non-stressed group proportions, regarding psychological, physiological and cognitive symptoms. The mean scores of the regular drug users group were significantly higher than those of the non-users / occasional drug users in these three subscales. Regular substance users scored higher than non-users/occasional substance users on all questions of psychological and cognitive symptoms $(p<.001)$ and on most questions of interpersonal and cognitive symptoms of stress. However, we did not detect significant differences between non/occasional and regular drug users concerning symptoms of interpersonal stress.

Table 2. Frequency of drug related problems, favorite drugs and use in the last 30 days in the total sample $(n=954)$, Non-users/occasional drug users $(n=758)$ and Regular drug users $(n=196)$. The data in the body of the table represent the percentage of positive answers

Use in the last 30 days

\begin{tabular}{lllllll}
\hline No use & $\begin{array}{l}1 \text { or } 2 \\
\text { times }\end{array}$ & $\begin{array}{l}3 \text { to } 9 \\
\text { times }\end{array}$ & $\begin{array}{l}10 \text { to } 20 \\
\text { times }\end{array}$ & $\begin{array}{l}\text { more than } \\
20 \text { times }\end{array}$ & $\begin{array}{l}\text { Drug-related } \\
\text { problems }\end{array}$ & $\begin{array}{l}\text { favorite } \\
\text { drug }\end{array}$ \\
\hline
\end{tabular}

\begin{tabular}{|c|c|c|c|c|c|c|c|}
\hline \multicolumn{8}{|l|}{ Alcohol } \\
\hline Total Sample & 48.2 & 26.7 & 16.4 & 5.7 & 3.0 & .8 & 8.0 \\
\hline Non-users/Occasional drug users & 57.3 & 27.3 & 11.1 & 2.5 & 1.7 & .3 & 2.8 \\
\hline Regular drug users & 8.6 & 24.1 & 39.0 & 19.5 & 8.6 & 3.1 & 30.1 \\
\hline \multicolumn{8}{|l|}{ Tobacco } \\
\hline Total Sample & 85.8 & 4.8 & 3.0 & 2.1 & 4.3 & .8 & 2.7 \\
\hline Non-users/Occasional drug users & 93.9 & 3.3 & 1.2 & .7 & 0.9 & - & .4 \\
\hline Regular drug users & 51.1 & 11.2 & 10.7 & 8.4 & 18.5 & 4.1 & 11.7 \\
\hline \multicolumn{8}{|l|}{ Analgesics (without prescription) } \\
\hline Total Sample & 68.8 & 20.3 & 6.8 & 1.8 & 2.2 & .1 & - \\
\hline Non-users/Occasional drug users & 71.3 & 20.4 & 5.0 & 1.2 & 2.0 & - & - \\
\hline Regular drug users & 59.0 & 20.0 & 13.8 & 4.1 & 3.1 & .5 & - \\
\hline \multicolumn{8}{|l|}{ Marijuana } \\
\hline Total Sample & 92.9 & 3.2 & 2.5 & .9 & .5 & .3 & 3.0 \\
\hline Non-users/Occasional drug users & 98.9 & .7 & .1 & .1 & .1 & - & 0.3 \\
\hline Regular drug users & 67.0 & 14.2 & 12.5 & 4.0 & 2.3 & 1.5 & 13.8 \\
\hline \multicolumn{8}{|c|}{ Inhalants, solvents (glue, aerosols, thinners, etc..) } \\
\hline Total Sample & 94.4 & 3.9 & .6 & .4 & .6 & .2 & .7 \\
\hline Non-users/Occasional drug users & 98.8 & 1.0 & - & - & .1 & - & - \\
\hline Regular drug users & 76.2 & 15.7 & 3.2 & 2.2 & 2.7 & 1.0 & 3.6 \\
\hline
\end{tabular}


Table 3. Percentage of non-users/occasional drug users and regular drug users classified according to stress category (non-stressed, vulnerable and stressed) and subscales scores (means \pm standard deviation) using the four subscales of symptoms (psychological, cognitive, physiological and interpersonal)

\begin{tabular}{|c|c|c|c|c|}
\hline Subscales of symptoms & $\begin{array}{l}\text { Non/ocasional users } \\
(n=758)(79.5 \%)\end{array}$ & $\begin{array}{l}\text { Regular users } \\
(n=196)(20.5 \%)^{\mathrm{a}}\end{array}$ & $\chi^{2}$ or $\mathrm{T}$ & $p$ \\
\hline \multicolumn{5}{|l|}{ Psychological Symptoms } \\
\hline Non-stressed & 89.0 & 11.0 & $\chi^{2}=12.0$ & $<.001$ \\
\hline Vulnerable & 81.0 & 19.0 & $\chi^{2}=.61$ & n.s. \\
\hline Stressed & 66.0 & 34.0 & $\chi^{2}=25.1$ & $<.001$ \\
\hline Score (means $\pm S D$ ) & $.92 \pm .70$ & $1.28 \pm .69$ & $\mathrm{~T}=-6.1$ & $<.001$ \\
\hline \multicolumn{5}{|l|}{ Cognitive Symptoms } \\
\hline Non-stressed & 95.1 & 4.9 & $\chi^{2}=42.7$ & $<.001$ \\
\hline Vulnerable & 83.5 & 16.5 & $\chi^{2}=3.67$ & $<.05$ \\
\hline Stressed & 57.2 & 42.3 & $\chi^{2}=78.3$ & $<.001$ \\
\hline Score (means $\pm S D$ ) & $.84 \pm .74$ & $1.53 \pm .63$ & $\mathrm{~T}=-11.6$ & $<.001$ \\
\hline \multicolumn{5}{|l|}{ Physiological Symptoms } \\
\hline Non-stressed & 84.1 & 15.9 & $\chi^{2}=3.3$ & $<.067$ \\
\hline Vulnerable & 81.4 & 18.6 & $\chi^{2}=.97$ & n.s. \\
\hline Stressed & 71.5 & 28.5 & $\chi^{2}=29.1$ & $<.001$ \\
\hline Score (means $\pm S D$ ) & $.95 \pm .74$ & $1.17 \pm .76$ & $\mathrm{~T}=-3.6$ & $<.001$ \\
\hline \multicolumn{5}{|l|}{ Interpersonal Symptoms } \\
\hline Non-stressed & 79.2 & 20.8 & $\chi^{2}=.02$ & n.s. \\
\hline Vulnerable & 81.1 & 19.9 & $\chi^{2}=.46$ & n.s. \\
\hline Stressed & 77.1 & 22.9 & $\chi^{2}=1.04$ & n.s. \\
\hline Score $($ means $\pm S D)$ & $.97 \pm .79$ & $1.00 \pm .82$ & $\mathrm{~T}=-.60$ & n.s \\
\hline
\end{tabular}

n.s. non-significant differences.

aPercentage observed in the total sample

Note: In the one sample $\chi^{2}$ test calculation to compare the proportion of non-users/occasional drug users and regular drug users in each stress category we considered as expected frequency the one observed in the total sample (79.5\% of non-users/ occasional drug users and $20.5 \%$ of regular drug users)

Table 4 shows the proportion of non-users/occasional drug users and regular drug users in each stress stage (without stress, alert, resistance, near exhaustion and exhaustion) and the means of the total scores in the SSA. We observed significantly higher scores in the group of regular drug users, which points to a higher frequency of stress in this group than in the group of non-users/occasional drug users. The proportions of regular drug users in the stages of exhaustion (32.9\%) and near exhaustion $(32 \%)$ were also significantly higher than would be expected if we consider the proportion of regular drug users in the total sample $(20.5 \%)$.

Table 5 presents the medians of Absolute Density in Substance Use Area of the DUSI-R questionnaire in the groups of regular and non/occasional drug users, classified according to their symptoms of psychological, cognitive, physiological and interpersonal stress. We observed a higher intensity of drug-related problems among students classified as stressed than among the non-stressed or vulnerable regarding psychological and cognitive symptoms. Considering the physiological symptoms of stress, the regular drug user students classified as "stressed" presented higher levels of drug-related problems than those considered "nonstressed". However, we did not detect any significant differences regarding interpersonal symptoms.

Table 6 shows the distribution of students considering stress type, category and stage, as well as drug use category, in the three age brackets. We observed a significant association between age, stress category and drug use. The proportion of regular drug users increased significantly with age $(4 \%$ among those under 14 years old, $20 \%$ among those between 14 and 16 , and $47 \%$ among those over 16 ). Similarly, we also observed an increase in the proportion of stressed students, mainly concerning cognitive and psychological symptoms $(20.7 \%$ and $19.2 \%$ among those under 14 and $43.3 \%$ and $34.3 \%$ among those over 16 , respectively). We did not detect significant differences between different age brackets in the proportion of "stressed" students with respect to physiological and interpersonal symptoms. 
Table 4. Percentage of non-users/occasional drug users and regular drug users in each stress stage and scores (means \pm SD) on the SSA scale

\begin{tabular}{lllll}
\hline & $\begin{array}{l}\text { Non/occasional users } \\
(n=758)(79.5 \%)\end{array}$ & $\begin{array}{l}\text { Regular users } \\
(n=196)(20.5 \%)\end{array}$ & $\chi^{2}$ or T & $p$ \\
\hline Stress stage & & & $\chi^{2}=15.8$ & $<.001$ \\
Without stress & 92.3 & 7.7 & $\chi^{2}=4.9$ & $<.03$ \\
Alert Stage & 86.8 & 13.2 & $\chi^{2}=.16$ & n.s. \\
Resistance Stage & 80.9 & 19.1 & $\chi^{2}=11.7$ & $<.001$ \\
Near exhaustion stage & 68.0 & 32.0 & $\chi^{2}=15.07$ & $<.001$ \\
Exhaustion stage & 67.1 & 32.9 & $\mathrm{~T}=-6.4$ & $<.001$ \\
Total scores (means $\pm S D)$ & $54 \pm 35$ & $74 \pm 33$ & & \\
\hline
\end{tabular}

n.s. non-significant differences.

Note: We used the one sample $\chi^{2}$ test to compare the proportion of non-users/occasional drug users and regular drug users in each stress category considering as expected frequency the one observed in the total sample $(79.5 \%$ of non-users/occasional drug users and $20.5 \%$ of regular drug users)

Given the expected proportion of regular drug users in the total sample $(4 \%, 20 \%$ and $47 \%$, respectively for the three age brackets $<14,14-16$ and $>16$ ), we observed a higher proportion of regular drug users among the stressed students with psychological symptoms $(14.6 \%, 32.7 \%$ and $52.5 \%)$ than among the non-stressed ones $(1.2 \%, 13.9 \%$ and $29.6 \%)$. This increased proportion of stressed students among drug users was observed regarding all types of stress but was particularly high in the 14-16 age bracket in relation to psychological, cognitive and physiological symptoms. Considering the regular drug users in the youngest age bracket, the proportion of stressed was 8-12 times higher than non-stressed regarding psychological, cognitive and physiological symptoms. There was a weakening in the relation between stress and drug use among those over age 16. The proportion of stressed regular drug users in this age bracket was only significantly higher (1.5 times) than expected with regard to cognitive symptoms, but similar to the expected ones in relation to interpersonal, psychological and physiological symptoms.

Table 5. Absolute Density of Problems in Substance Use Area (DA1) of the DUSI-R questionnaire (median and semi interquartile range) in the groups classified according to their use of drugs (non-users/occasional users and regular users) considering stress category (nonstressed, vulnerable, stressed) and type of symptoms (psychological, cognitive, physiological and interpersonal) by the SSA Scale. Data expressed as median and semi interquartile range (SIQR)

\begin{tabular}{|c|c|c|c|c|c|c|c|}
\hline & \multicolumn{7}{|c|}{ Classification according to the intensity of stress symptoms } \\
\hline & \multirow{2}{*}{$\frac{\text { Non- stressed (NE) }}{\text { Median (ISIQ) }}$} & \multirow{2}{*}{$\frac{\text { Vulnerable (V) }}{\text { Median (ISIQ) }}$} & \multirow{2}{*}{$\frac{\text { Stressed (S) }}{\text { Median (ISIQ) }}$} & \multirow{2}{*}{$\frac{\mathrm{K}-\mathrm{W}}{p}$} & \multicolumn{3}{|c|}{ Mann- Whitney } \\
\hline & & & & & $\mathrm{NE} \times \mathrm{V}$ & NE $\times \mathrm{E}$ & $\mathrm{V} \times \mathrm{E}$ \\
\hline \multicolumn{8}{|c|}{ Psychological Symptoms } \\
\hline DA 1 - Non-users & $0(0)$ & $0(0)$ & $0(3.3)$ & $.009^{*}$ & n.s. & $.002^{*}$ & $.03^{*}$ \\
\hline DA 1 - Regular Users & $26.7(6.7)$ & $33.3(6.7)$ & $40(13.3)$ & $.02^{*}$ & n.s. & $.02^{*}$ & $.04^{*}$ \\
\hline \multicolumn{8}{|l|}{ Cognitive Symptoms } \\
\hline DA 1 - Non-users & $0(0)$ & $0(0)$ & $0(3.3)$ & $.001^{*}$ & $.003^{*}$ & $.001^{*}$ & n.s. \\
\hline DA 1 - Regular Users & $20(6.7)$ & $33.3(10)$ & $40(10)$ & $.004^{*}$ & $.04^{*}$ & $.003^{*}$ & $.04^{*}$ \\
\hline \multicolumn{8}{|c|}{ Physiological Symptoms } \\
\hline DA 1 - Non-users & $0(0)$ & $0(0)$ & $0(0)$ & n.s. & n.s. & n.s. & n.s. \\
\hline DA 1 - Regular Users & $33.3(10)$ & $33.3(6.7)$ & $40(13.3)$ & $.03^{*}$ & n.s. & $.01^{*}$ & n.s. \\
\hline \multicolumn{8}{|c|}{ Interpersonal Symptoms } \\
\hline DA 1 - Non-users & $0(0)$ & $0(0)$ & $0(0)$ & n.s. & n.s. & n.s. & n.s. \\
\hline DA 1 - Regular Users & $33.3(6.7)$ & $33.3(10)$ & $33.3(13.3)$ & n.s. & n.s. & n.s. & n.s. \\
\hline
\end{tabular}

$\mathrm{SIQR}-$ Semi InterQuartile Range $=\frac{\mathrm{Q} 3-\mathrm{Q} 1}{2}$

${ }^{*} p \leq 0.001$ n. s. non-significant differences 


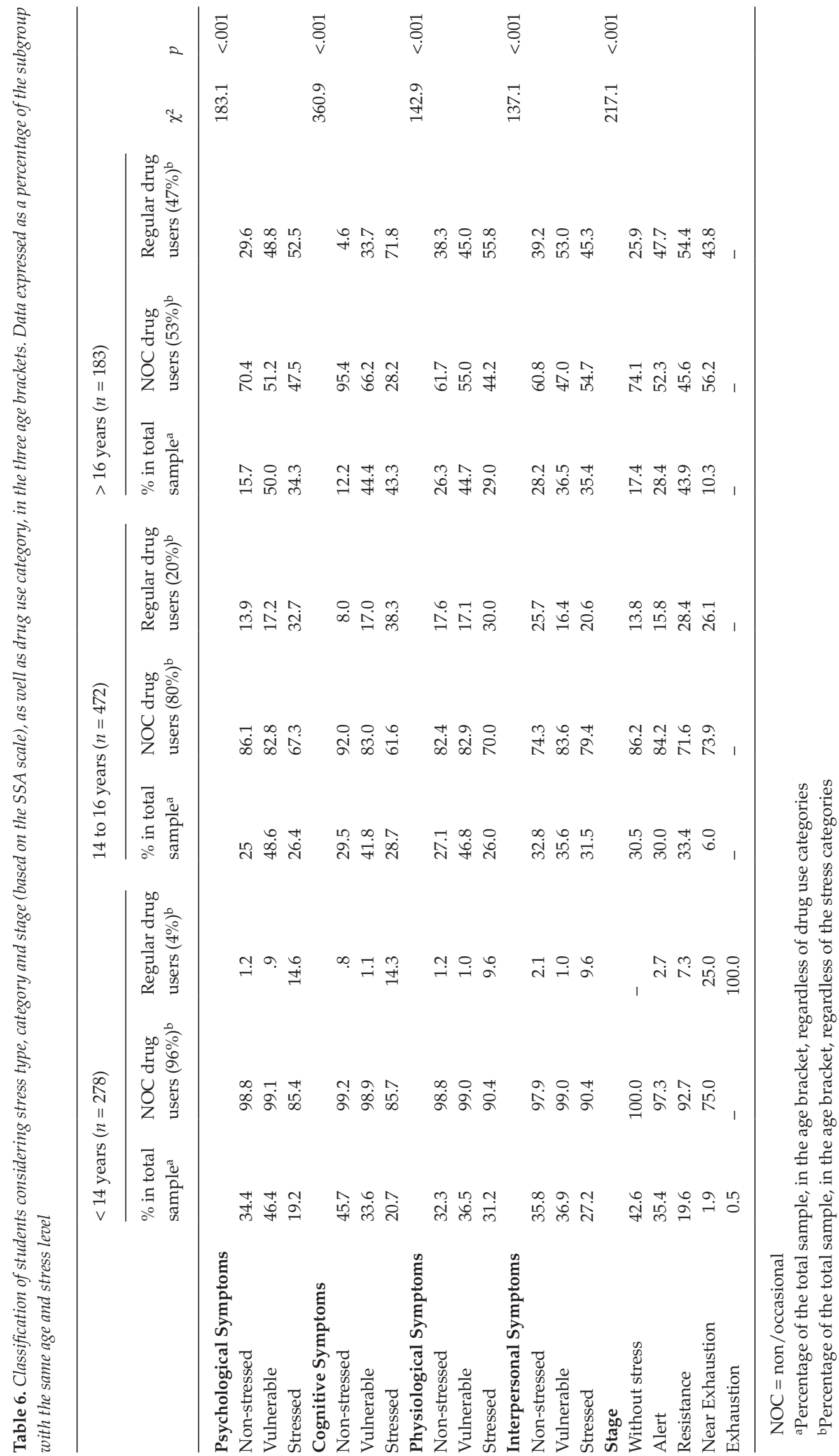


Regarding stress, regular drug users appear to be in the most advanced stages. Similarly to the observed regarding psychological and cognitive symptoms, the relationship between drug use and stress stage was more striking among younger adolescents. All users in the youngest age bracket presented some level of stress, the majority of them being in its most advanced stages. Most of the regular drug users in the 14-16 age bracket were in the stages of resistance or near exhaustion. There was a lower proportion of non-stressed regular drug users among those over $16(25.9 \%)$ and a higher proportion in the stage of resistance $(54.4 \%)$ than would be expected for this age bracket (47\%).

The analysis of the correlation among the four types of stress indicated a significant correlation between psychological and physiological symptoms $\left(r_{s}=.65\right)$, but not between interpersonal and cognitive symptoms $\left(r_{s}=.31\right)$ neither between interpersonal and physiological symptoms $\left(r_{s}=.40\right)$.

\section{Discussion}

Although there are many studies on the relationship between drug use and stress, very few focused on the early phases of adolescence (Aseltine \& Gore, 2000; Tarter et al., 1995; Wills, 1986), considering the different kinds and stages of stress. This is the main contribution of the present study. We observed a significant association between stress and drug use, which was stronger in the younger age groups, indicating this is an important risk factor which should be taken into account in the planning of prevention and intervention programs.

As expected, we observed that the use of drugs and stress increases significantly with age. Regular drug users presented higher scores than non-users/occasional drug users in all questions on psychological and cognitive stress symptoms, as well as in most of the questions on physiological and interpersonal symptoms. While the physiological stress symptoms stood out in the youngest age bracket, the interpersonal stress symptoms were more frequent in the 14-16 age brackets. Cognitive stress symptoms were particularly prominent among regular drug users. The prominence of different symptoms of stress in each age bracket could be useful in identifying adolescents at a higher risk of drug use. Thus, the presence of psychological and cognitive stress symptoms among adolescents under age 16 could be used as an indicator of higher risk for drug use.

We observed a smaller number of regular drug users in the beginning of elementary school than in the students in high school, with an increase of use among those in the $8^{\text {th }}$ grade of elementary school and in the $9^{\text {th }}$ grade of high school (i.e., in the finishing and starting grades of the two major Brazilian school cycles). This suggests that drug use may serve as a "rite of passage" among adolescents.

Another aspect that requires consideration is the fact that older adolescents need to make more stressgenerating decisions than the younger ones. Langston \& Cantor (1989) pointed out that academic life may be a great source of stress and that the transition to new academic levels generates an increase in responsibilities, anxiety and competitiveness, which induces stress. On the other hand, our findings on the lower rate of increase in drug use from the middle (14-16) to the oldest age bracket (16 or more) than from the youngest $(<14)$ to the middle one, are in accordance with data reported by other authors who also found evidence that the strength of the association between stress and alcohol use decreases with age (Aseltine \& Gore, 2000; Hoffmann et al. 2000). This suggests that older adolescents may have developed coping strategies other than drug use. These may be factors that need to be considered in prevention efforts. Parke \& Bhavnagri (1989) observed that as youngsters develop, they begin to have control over some aspects of their lives and participate more actively in their environment. At the same time, the family influence decreases and they become less resistant to peer influence (Steinberg \& Silverberg, 1986).

In general, our data corroborate those obtained by Seltzer \& Oechsli (1985) and Wills (1986), who identified stress as a factor that can trigger substance use, as a way to cope with it. They are also in accordance with a recent study conducted in South Africa, with students aged from 12 to 17 years old, Brook, Rubenstone, Zhang, Morojele, \& Brook (2011) suggested environmental stressors may be associated with smoking and alcohol use, as well as with diminished psychological and physical well-being. Their findings are compatible with those reported by Vazsonyi et al. (2008) who compared two groups of students from different cultural backgrounds (from Georgia, US and Switzerland) regarding the Jessor's problem behavior theory. Those authors concluded the problem-behavior theory holds value in understanding the etiology of adolescent problem behaviors outside the United States.

Our study differs from others because to the best of our knowledge it is the first study with teenagers that focused on the relation between stress and the use of drugs, considering the different kinds of stress symptoms and their time of occurrence. The use of a student population allowed us to evaluate adolescents with different degrees of stress without being restricted to populations that suffered stress of the post-traumatic type, which is the case of most studies published on this topic. Franco, Hubbard, \& Martin (1998) reported that much of the data evaluating the relationship between substance abuse and stress is conflicting due 
to the complexity of the interaction between these two factors. Those authors emphasized the importance of studying factors such as the types of stressors, their duration, the family climate, the different psychological or physical reactions to stressors and the capacity to cope with stress. However, they found it difficult to precisely measure stress levels and the level of substance abuse or dependence. In this study, the use of standardized instruments that had been previously tested in the target population allowed us to study the relationship between drug use, the four different types of stress symptoms, their time of occurrence and other factors such as age that influence this relationship.

The significant association between stress and drug use was strengthened by the finding that most of the regular drug users were in the resistance, near exhaustion or exhaustion stress stages, which indicates concomitant chronic stress and drug use. Among other factors associated with drug use, we can highlight the poor family relationships, inadequate school performance and better socioeconomic characteristics of the regular users. In general, the use of alcohol and other drugs observed in this study was higher than that reported in the IV Survey on the Use of Drugs carried out with students in elementary and high school in the city of São Paulo (Galduróz et al., 1997). While the use of alcohol in the previous month in that survey was $37 \%$, it was $51.2 \%$ in our study. The same was true with regard to tobacco $(14.2 \%$ vs. $12.4 \%)$, marijuana $(7.1 \%$ vs. $2.1 \%$ ), solvents ( $5.6 \%$ vs. $2.9 \%$ ) and other drugs. The discrepancy in the results may be due to differences in the profile of the sample (e.g., inclusion of private schools), the different methodology of the studies or to an increase in drug use among adolescents after some years.

In this study we observed that the students often mentioned the use of analgesics without prescription $(31.2 \%)$, which suggests that self-medication is already common in this age group. It is interesting to note that the use of analgesics was significantly higher in the group of regular drug users (41\%) than in the group of non-users/occasional drug users $(28.7 \%)$. This early behavior of self-medication might be associated with stress and with use of psychoactive drugs.

The academic underachievement in the group of regular drug users proved to be significant when compared to the group of non-users/occasional drug users. Our results are in accordance with the data from other studies that show an association between the use of psychoactive substances and poor school performance (Galduróz et al., 1997; Moos, Finney, Ouimette, \& Suchinsky, 1999). However, it is important to consider that factors other than the use of psychoactive substances may contribute to a poor school performance.
Butters (2002) observed that family stressors might negatively impact various aspects in the life of an adolescent, including delinquency, drug use and school problems. We also found significant differences in family relationships between the regular and the non/ occasional drug users groups. Kandel, Davies, Karus, \& Yamaguchi (1986) noticed that students who abused illicit drugs reported an unsatisfactory relationship with their parents and higher rates of delinquency in addition to poor school performance. Rosenberg \& Anthony (2001) found that the most aggressive youths were about five times more likely to be offered drugs for purchase; however, this association was much attenuated when levels of delinquency were taken into account.

In the present study, we observed that most of the regular drug users belonged to the upper/ uppermiddle socioeconomic classes as classified by the norms of the Brazilian Association of Market Research Institutes ([ABIPEME], 1978). These data are in agreement with other studies, which also found a larger number of users among upper and uppermiddle classes (Baus, Kupek, \& Pires, 2002). Most regular drug users in our sample were studying at private schools. This suggests that a higher purchasing power may facilitate the use of drugs.

In summary, when compared to non/occasional drug users, regular drug user adolescents presented higher levels of psychological, cognitive and physiological symptoms of stress, being in the most advanced stages of stress (near exhaustion and exhaustion). Besides, the association between drug use and stress was even stronger in the youngest age group (11 to 13 years old).

Even though the conclusions of the present work may not be completely generalized because the sample was not representative of the Brazilian adolescent population, the data suggest a strong association between the presence of stressful factors in early adolescence and the use of drugs and alert to the need of early screening of and intervention on both drug use and stressful situations.

\section{References}

ABIPEME. (1978). Proposição para um novo critério de classificação socioeconômica [Proposition for a new criterion of social-economic classification]. São Paulo, Brazil: Mimeo.

Agnew R., \& White H. R. (1992). An Empirical test of general strain theory. Criminology, 30, 475-500. http:/ /dx.doi.org/10.1111/j.1745-9125.1992.tb01113.x

Aseltine R. H. Jr., \& Gore S. L. (2000). The variable effects of stress on alcohol use from adolescence to early adulthood. Substance Use \& Misuse, 35, 643-668. http:/ / dx.doi. org /10.3109/10826080009148415 
Battista S. R., Stewart S. H., \& Ham L. S. (2010). A critical review of laboratory-based studies examining the relationships of social anxiety and alcohol intake. Current Drug Abuse Reviews 3, 3-22. http:/ / dx.doi. org /10.2174/1874473711003010003

Baus J., Kupek E., \& Pires M. (2002). Prevalence and risk factors associated with drug use among school students, Brazil. Revista de Saude Publica, 36, 40-46. http:/ /dx.doi. org/10.1590/S0034-89102002000100007

Brook D. W., Rubenstone E., Zhang C., Morojele N. K., \& Brook J. S. (2011). Environmental stressors, low well-being, smoking, and alcohol use among South African adolescents. Social Science \& Medicine, 72, 1447-1453. http:/ / dx.doi.org/10.1016/j.socscimed.2011.02.041

Butters J. E. (2002). Family stressors and adolescent cannabis use: A pathway to problem use. Journal of Adolescence, 25, 645-654. http:/ / dx.doi.org/10.1006/jado.2002.0514

Caldwell E. E., \& Riccio D. C. (2010). Alcohol selfadministration in rats: Modulation by temporal parameters related to repeated mild social defeat stress. Alcohol, 44, 265-274. http://dx.doi.org/10.1016/j.alcohol. 2010.02.012

Campbell J. C., Szumlinski K. K., \& Kippin T. E. (2009). Contribution of early environmental stress to alcoholism vulnerability. Alcohol, 43, 547-554. http:/ / dx.doi.org/ 10.1016/j.alcohol.2009.09.029

Carlini E. A., Noto A. R., Sanchez Z. M., Carlini C. M. A., Locatelli D. P., Abeid L. R., ... Moura Y. G. (2010). VI Levantamento nacional sobre o consumo de drogas psicotrópicas entre estudantes do ensino fundamental e médio das redes pública e privada de ensino nas 27 capitais brasileiras. [VI National survey on psychotropic drug use among students of elementary and higher education of private and public education in the 27 brazilian capitals]. São Paulo, Brazil, Centro Brasileiro de Informações Sobre Drogas Psicotrópicas (CEBRID).

Cerbone F. G., \& Larison C. L. (2000). A bibliographic essay: The relationship between stress and substance use. Substance Use E Misuse, 35, 757-786. http:/ / dx.doi. org/10.3109/10826080009148420

Conger J. J. (1956). Alcoholism: Theory, problem and challenge. II. Reinforcement theory and the dynamics of alcoholism. Quarterly Journal of Studies on Alcohol, 17, 296-305.

Dalla-Dea H. R., De Micheli D., \& Formigoni M. L. (2003). Effects of identification and usefulness of the Lie Scale of the Drug Use Screening Inventory (DUSI-R) in the assessment of adolescent drug use. Drug and Alcohol Dependence, 72, 215-223. http:/ /dx.doi.org/10.1016/ S0376-8716(03)00219-9

De Micheli D., \& Formigoni M. L. (2000). Screening of drug use in a teenage brazilian sample using the Drug Use Screening Inventory (DUSI-R). Addictive Behaviors, 25, 683-691. http:/ / dx.doi.org/10.1016/S0306-4603(00)00065-4

De Micheli D., \& Formigoni M. L. (2002a). Are reasons for the first use of drugs and family circumstances predictors of future use patterns? Addictive Behaviors, 27, 87-100. http:/ /dx.doi.org/10.1016/S0306-4603(00)00167-2

De Micheli D., \& Formigoni M. L. (2002b). Psychometric properties of the brazilian version of the drug use screening inventory. Alcoholism, Clinical and Experimental Research, 26, 1523-1528. http:/ /dx.doi.

org/10.1111/j.1530-0277.2002.tb02451.x

De Micheli D., \& Formigoni M. L. (2004). Drug use by brazilian students: Associations with family, psychosocial, health, demographic and behavioral characteristics. Addiction, 99, 570-578. http://dx.doi.org/10.1111/j.1360-0443. 2003.00671.x

DeMartini K. S., \& Carey K. B. (2011). The role of anxiety sensitivity and drinking motives in predicting alcohol use: A critical review. Clinical Psychology Review, 31, 169-177. http://dx.doi.org/10.1016/j.cpr.2010.10.001

Erb S. (2010). Evaluation of the relationship between anxiety during withdrawal and stress-induced reinstatement of cocaine seeking. Progress in Neuro-Psychopharmacology $\mathcal{E}$ Biological Psychiatry, 34, 798-807. http://dx.doi.org/ 10.1016/j.pnpbp.2009.11.025

Ernst M., \& Korelitz K. E. (2009). Cerebral maturation in adolescence: Behavioral vulnerability. Encephale, 35, S182-S189. http://dx.doi.org/10.1016/S00137006(09)73469-4

Ernst M., Romeo R. D., \& Andersen S. L. (2009). Neurobiology of the development of motivated behaviors in adolescence: A window into a neural systems model. Pharmacology, Biochemistry, and Behavior, 93, 199-211. http:/ / dx.doi.org/10.1016/j.pbb.2008.12.013

Farber P. D., Khavari K. A., \& Douglass F. M. T. (1980). A factor analytic study of reasons for drinking: Empirical validation of positive and negative reinforecement dimensions. Journal of Consulting and Clinical Psychology, 48, 780-781. http:/ /dx.doi.org/10.1037/ /0022-006X. 48.6.780

Franco S. E., Hubbard S. W., \& Martin P. R. (1998). Stress and Addiction. In J. R. Hubbard \& E. A. Workman (Eds.), Handbook of stress medicine. An organ system approach (Vol. 1). New York, NY: CRC-Press.

Galduróz J. C. F., Noto A. R., \& Carlini E. A. (1997). IV Levantamento sobre o uso de drogas entre estudantes de $1^{\circ}$. e $2^{\circ}$. graus em 10 capitais brasileiras [IV survey on drug use among students in elementary and high school in

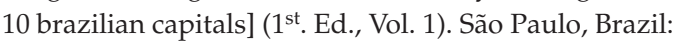
Centro Brasileiro de Informações sobre Drogas Psicotrópicas (CEBRID), Universidade Federal de São Paulo.

Galduróz J. C. F., Noto A. R., Nappo S. A., \& Carlini E. A. (2005). Use of psychotropic drugs in Brazil: Household survey in the 107 biggest Brazilian cities-2001. Revista Latino Americana de Enfermagem, 13 (Special number), 7.

Hoffmann J. P., \& Su S. S. (1998). Stressful life events and adolescent substance use and depression: Conditional and gender differentiated effects. Substance Use \& Misuse, 33, 2219-2262. http:/ /dx.doi.org/10.3109/10826089809056256

Hoffmann J. P., Cerbone F. G., \& Su S. S. (2000). A growth curve analysis of stress and adolescent drug use. Substance Use E Misuse, 35, 687-716. http:/ /dx.doi.org/10.3109/ 10826080009148417

Kandel D. B., Davies M., Karus D., \& Yamaguchi K. (1986). The consequences in young adulthood of adolescent drug involvement. An overview. Archives of General Psychiatry, 
43, 746-754. http://dx.doi.org/10.1001/ archpsyc.1986.01800080032005

Kirisci L., Mezzich A., \& Tarter R. (1995). Norms and sensitivity of the adolescent version of the drug use screening inventory. Addictive Behaviors, 20, 149-157. http:/ / dx.doi.org/10.1016/0306-4603(94)00058-1

Koch-Hattem A., \& Denman D. (1987). Factors associated with young adult alcohol abuse. Alcohol and Alcoholism, 22, 181-192.

Kushner M. G., Sher K. J., \& Beitman B. D. (1990). The relation between alcohol problems and the anxiety disorders. The American Journal of Psychiatry, 147, 685-695.

Langston C. A., \& Cantor N. (1989). Social anxiety and social constraint: When making friends is hard. Journal of Personality and Social Psychology, 56, 649-661. http:/ / dx.doi.org/10.1037/ /0022-3514.56.4.649

Lipp M. E. N. (2000). Manual do inventário de sintomas de stress em adultos de Lipp (ISSL) [Lipp's manual inventory stress symptoms in adults-ISSL]. São Paulo, Brazil: Casa do Psicólogo.

Lucarelli M. D. M., \& Lipp M. E. N. (1999). Validity of the child stress symptoms inventory. Psicologia Reflexão e Crítica, 12, 71-88. http:/ /dx.doi.org/10.1590/S010279721999000100005

Moos R. H., Finney J. W., Ouimette P. C., \& Suchinsky R. T. (1999). A comparative evaluation of substance abuse treatment: I. Treatment orientation, amount of care, and 1-year outcomes. Alcoholism, Clinical and Experimental Research, 23, 529-536. http:/ / dx.doi.org/ 10.1111/j.1530-0277.1999.tb04149.x

Parke R. D., \& Bhavnagri N. (1989). Parents as managers of children's peer relationships. In D. Belle (Ed.), Childrens's social networks and social supports. New York, NY: John Wiley \& Sons.

Rosenberg M. F., \& Anthony J. C. (2001). Aggressive behavior and opportunities to purchase drugs. Drug and Alcohol Dependence, 63, 245-252. http:/ /dx.doi.org/ 10.1016/S0376-8716(00)00213-1

Sayette M. A. (1999). Does drinking reduce stress? Alcohol and Research Health, 23, 250-255.

Seltzer C. C., \& Oechsli F. W. (1985). Psychosocial characteristics of adolescent smokers before they started smoking: Evidence of self-selection. A prospective study. Journal of Chronic Diseases, 38, 17-26. http:/ /dx.doi.org/ 10.1016/0021-9681(85)90004-9

Selye H. (1956). The stress of life (Vol. 1). New York, NY: McGraw-Hill.

Shahtahmasebi S., \& Berridge D. (2009). A longitudinal analysis of teenage drinking patterns. International Journal of Adolescent Medicine and Health, 21, 371-385. http:/ /dx.doi.org/10.1515/IJAMH.2009.21.3.371

Silva L. V., Malbergier A., Stempliuk V. de. A., \& de Andrade A. G. (2006). Factors associated with drug and alcohol use among university students. Revista de Saude Publica, 40, 280-288. http://dx.doi.org/10.1590/ S0034-89102006000200014

Sinha R. (2001). How does stress increase risk of drug abuse and relapse? Psychopharmacology, 158, 343-359. http:/ /dx.doi.org/10.1007/s002130100917

Steinberg L., \& Silverberg S. B. (1986). The vicissitudes of autonomy in early adolescence. Child Development, 57, 841-851. http:/ /dx.doi.org/10.1111/j.1467-8624.1986. tb00250.x

Tarter R. E., Blackson T., Brigham J., Moss H., \& Caprara G. V. (1995). The association between childhood irritability and liability to substance use in early adolescence: A 2-year follow-up study of boys at risk for substance abuse. Drug and Alcohol Dependence, 39, 253-261. http://dx.doi.org/ 10.1016/0376-8716(95)01175-6

Terra M. B., Barros H. M., Stein A. T., Figueira I., Jorge M. R., Palermo L. H., ... Da Silveira D. X. (2006). Social anxiety disorder in 300 patients hospitalized for alcoholism in Brazil: High prevalence and undertreatment. Comprehensive Psychiatry, 47, 463-467. http:/ /dx.doi. org/10.1016/j.comppsych.2006.02.004

Tricoli V. A. C. (2002). Escala de Stress para Adolescentes: Construção e Validação. [Stress Scale for Adolescents: Construction and validation]. Pontifícia Universidade Católica de Campinas, Campinas, Brazil.

Ungless M. A., Argilli E., \& Bonci A. (2010). Effects of stress and aversion on dopamine neurons: Implications for addiction. Neuroscience and Biobehavioral Reviews, 35, 151-156. http://dx.doi.org/10.1016/ j.neubiorev.2010.04.006

Vazsonyi A. T., Chen P., Young M., Jenkins D., Browder S., Kahumoku E., ... Michaud P. A. (2008). A test of Jessor's problem behavior theory in a Eurasian and a Western european developmental context. The Journal Adolescent Health, 43, 555-564. http:/ /dx.doi.org/10.1016/ j.jadohealth.2008.06.013

Wechsler H., Davenport A., Dowdall G., Moeykens B., \& Castillo S. (1994). Health and behavioral consequences of binge drinking in college. A national survey of students at 140 campuses. The Journal of the American Medical Association, 272, 1672-1677. http://dx.doi.org/10.1001/ jama.1994.03520210056032

Weiss F., Ciccocioppo R., Parsons L. H., Katner S., Liu X., Zorrilla E. P., Richter R. R. (2001). Compulsive drugseeking behavior and relapse. Neuroadaptation, stress, and conditioning factors. Annals of the New York Academy of Sciences, 937, 1-26. http://dx.doi.org/10.1111/ j.1749-6632.2001.tb03556.x

Wills T. A. (1986). Stress and coping in early adolescence: Relationships to substance use in urban school samples. Health Psychology, 5, 503-529. http:/ /dx.doi. org $/ 10.1037 /$ / 0278-6133.5.6.503 